\title{
Land Use Patterns under Ecological and Intensive Constraints--Scenario Simulation Based on SLEUTH
}

\author{
Jie Jin ${ }^{1,2, *}$, Yue Zhou ${ }^{1}$ and Hong Zhang ${ }^{2}$ \\ ${ }^{1}$ Kunming University of Science and Technology, Kunming, China \\ ${ }^{2}$ Yunnan University of Finance and Economics, Kunming, China \\ *Corresponding author
}

\begin{abstract}
For urbanization in plateau lake basins, city planning needs to balance the tradeoff between urban growth and preservation of ecological environment by adopting intensive land use and maintaining sufficient open space. This research designs and evaluates four land use types in Dianchi Lake basin, Yunnan Province, China: development without constraints, ecologically constrained development, intensive land use development, and ecologically-constrained intensive land use development. The SLEUTH model is used to examine the four scenarios, and suggests that the ecologically constrained intensive land use development pattern outperform others. The scenario strikes a nice balance between the development across the whole urbanicity spectrum (i.e., City-Town-Village or CTV) and protecting the ecological environment in the Dianchi Lake basin. Related policy recommendations are also proposed.
\end{abstract}

Keywords-ecological constraints; City-Town-Village (CTV); intensive land use; SLEUTH; Dianchi Lake basin

\section{INTRODUCTION}

Land use changes result in significant impacts on natural environment and alter ecological processes. Studying land use changes and corresponding impacts on ecological environment offers insight into regional sustainable development and protection of ecological systems [1]. Land use change in lake basins is a major factor affecting the regional ecological environment in plateau regions such as Yunnan Province, China [2]. For example, land use change across the whole urbanicity spectrum (i.e., City-Town-Village or CTV) and urban land expansion under the current pro-growth (or urban sprawl) policy are found to have major negative impacts on the water environment of lakes and the ecological environment of the basins [3-5]. Specifically, the urban land expansion resulted from decades of pro-growth policy has, to some extent, destroyed the regional ecological environment, and calls for a sustainable land use practice to protect the ecological environment [6]. Endless expansion of developed land under the current urban sprawl policy needs to be replaced by promoting intensive land use pattern, saving sufficient green space and making land development ecologically-friendly. This is critical for maintaining a healthy cycle for a regional ecological system. Only by doing so, we may undergo the urbanization and economic development while protecting the ecological environment in the plateau lake basin $[7,8]$. This requires us to strike the right balance between intensive land use development (for economic development) and ecological-constrained development (for protecting the regional eco-system)[9]. This research designs and evaluates four land use patterns in Dianchi Lake basin.SLEUTH model is used to implement and examine the four scenarios. The objective is to seek the best land use pattern in order to balance the lake ecological environment protection and regional urbanization and economic development.

\section{STUDY AREA AND DATA SOURCES}

\section{A. Study Area}

First, confirm that you have the correct template for your Dianchi Lake basin is located in the Yunnan-Guizhou Plateau, with longitude ranging $102^{\circ} 29^{\prime} 11.21^{\prime \prime} \sim 103^{\circ} 0^{\prime} 51.16 "$ \& latitude ranging $24^{\circ} 28^{\prime} 19.11^{\prime \prime} 25^{\circ} 27^{\prime} 29.44^{\prime \prime}$. It is about 1900 meters above the sea level, surrounded by mountains and hills. The total area is $2920 \mathrm{~km}^{2}$, and the total population is 3.5 million.

\section{B. Data}

Major datasets for the study include the RS satellite imagery associated with four time periods 1974, 1988, 1998, and 2008. Furthermore, Kunming and Dianchi Lake historical and contemporary data on urban development and design, land use,ecological environment,city planning, the 2nd national land use survey data, land use plan (2006-2020), Dianchi Lake wetland construction plan, 12th Five-year Plan of Dianchi Lake environment, Dianchi Lake landscape tourism plan, Kunming transportation maps, Kunming ecological barrier construction plan, new Kunming construction plan, and socioeconomic development plan.

\section{DESIGN OF DEVELOPMENT SCENARIOS}

Foremost, protection of lake ecological environment should be the prerequisite for intensive land use development in plateau lake basin. For example, urban development should not occupy the lake's ecological barrier land but protect the forest, garden, farm land and water area in the lake basin [10]. In addition, we should use the land more efficiently, strictly control the City-Town-Village construction scale, avoid the 'concentric' expansion model for the spatial layout, advocate a compact, intensive and collective expansion pattern, and increase the green space in the city.

Therefore, a reasonable CTV development pattern for Dianchi Lake basin under the ecological constraints should be 
planned by taking into account the landscape ecology, intensive land use, and compact grouping [11-13]. Specifically, the following aspects should be considered:landscape ecological constraints; intensive land use;develop the center town; optimize rural residential places;compactly grouping development.Based on the above 'rules', we designed four scenarios for the Dianchi Lake basin (see “ Figure 1”):

\section{A. Scenario 1 - Development without Constraints}

This scenario is to develop CTV in the Dianchi Lake basin as it is, without considering the ecological impact and the capacity of land. Specifically, it only considers the transportation, infrastructure, socio-economic condition, slope of land (a basic factor considered by Cellular Automata simulation) and so on.

\section{B. Scenario 2-Ecologically-Constrained Development}

Ecologically-constrained development is defined as an extension to the first scenario by adding the constraint of ecological land use. Specifically, it controls the need for land by the CTV development, especially around the wetland and lake ecological protection area, and encourages to the land use with minimum impacts on the eco-system. In addition, it also imposes a minimum green space in a city. In short, this scenario considers ecological constraints but not the land capacity and structure of the CTV.

\section{Scenario 3 - Intensive Land Use Development}

This scenario also represents an extension to the first scenario that considers, however, land capacity rather than ecological constraints in the CTV development. For instance, it increases urban population and decreases rural population, increases the urban land and decreases rural land according to the recommendation of Kunming's 'metropolitan-wide urbanization'. Furthermore, it adjusts the structure, function and spatial layout of the CTV for land use efficiency. Note that this scenario does not consider the ecological constraints of Dianchi Lake basin.

\section{Scenario 4-Ecologically-Constrained Intensive Land Use Development}

This scenario works as an integration of scenario 2 (ecologically-constrained development) and scenario 3 (intensive land use development), and is thus a comprehensive development pattern. It coordinates the development of CTV with the protection of ecological environment in the Dianchi Lake basin to achieve a 'win-win' outcome in terms of regional economic development and eco-system management and protection.

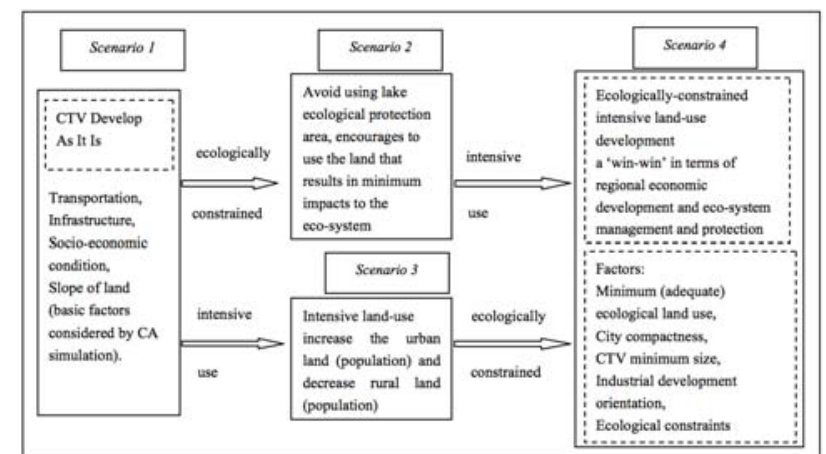

FIGURE I. CITY-TOWN-VILLAGE INTENSIVE LAND USE SCENARIO.

\section{IMPLEMENTATION OF DEVELOPMENT SCENARIOS}

Cellular Automata (CA) is often used to model the land use change from the existing development pattern and has shown promising results [15]. The research considers indicators such as ecological environment limit and intensive land use limit in the CA model to adjust the development rates in different regions [16]. This can help predict the urban development under ecological constraints. The SLEUTH model has demonstrated its advantages in terms of model transferability [17], prediction accuracy of urban growth, landscape change, as well as environmental impacts assessment [18]. This research adopts the auto-adjust city dynamic stimulation system from the SLEUTH to simulate and model the dynamic process of urban sprawl in Dianchi Lake basin [19-21]. Specifically, we use it to simulate the growth of the city, its spatial boundary and roads, among others based on a series of control indices such as spread coefficient, reproduction coefficient, expansion coefficient, slope coefficient, road weights, as well as the customized coefficients which accounts for ecological limit and intensive land use [22].

\section{ANALYSIS RESUlTS AND DISCUSSION}

We implemented the four scenarios in the SLEUTH CA model, and simulated the city growth in 1988, 1998 and 2008. In comparison to the practice data, we calculated the Kappa coefficient is $0.4,0.43,0.55$. respectively. We also simulated the city growth in 2015, 2020, and 2028. See Table I for results. Based on the 2020 Kunming city planning for Dianchi Lake basin, the CTV developed land should not exceed 620 $\mathrm{km}^{2}$. Therefore, we adopted the model with a cumulative percentage $>80 \%$. 
TABLE I. SIMULATION RESULTS FOR 2015, 2020, AND 2028

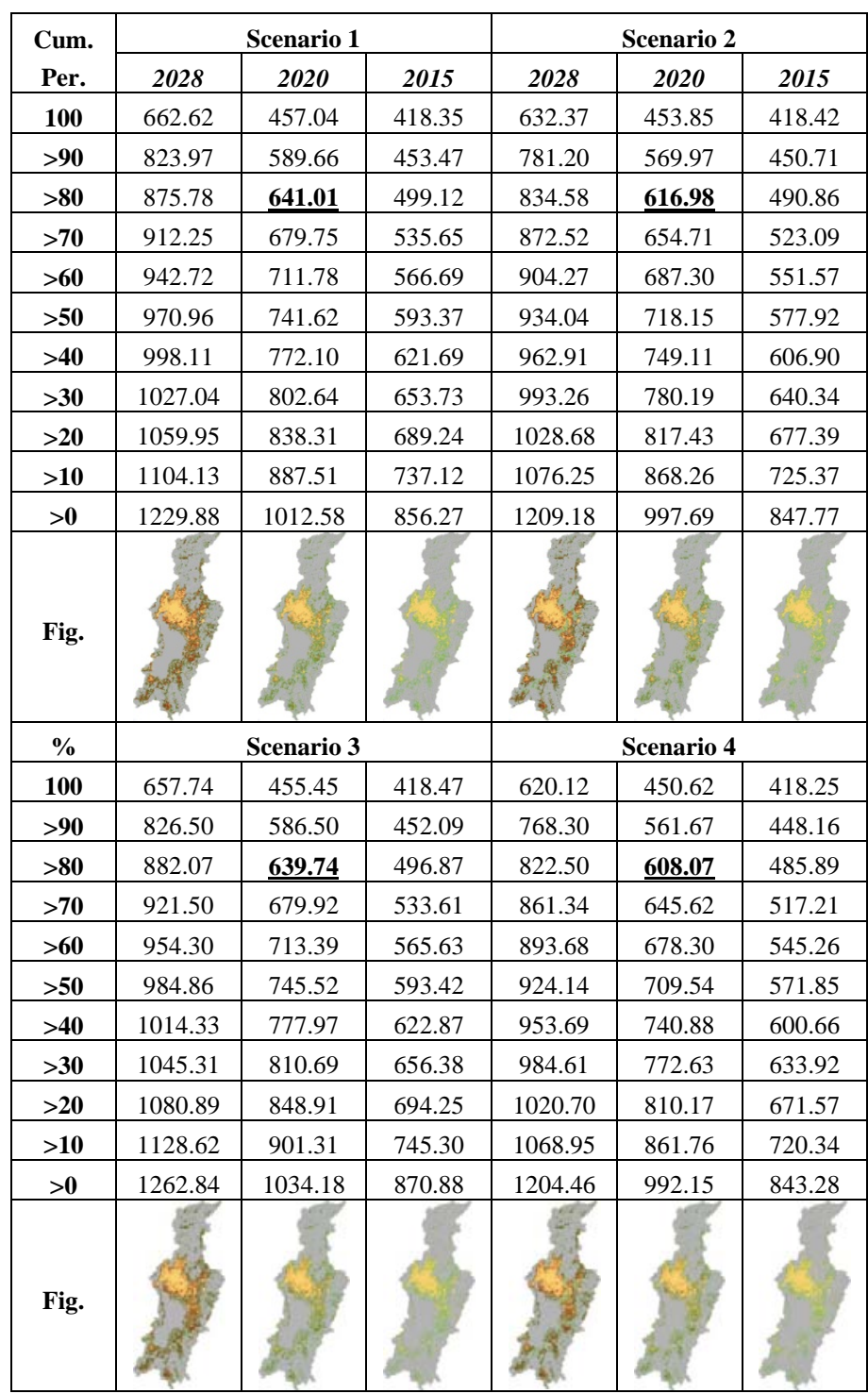

\section{CONCLUSIONS}

Based on the comparison among the above four land use development scenarios, summarized as follows.

First, the cumulative percentage declines over time in all four scenarios, and the developed land increases significantly, which corresponds to the development of CTV.

Secondly, scenarios 1 and 3 without ecological constraints do not save land for development as much as scenarios 2 and 4 under ecological constraints.

Thirdly, scenario 4 yields less developed land use for CTV than scenario 2 or 3 at all time periods. This indicates that the intensive land use can benefit from imposing the ecological constraints, and thus the CTV development under the ecological constraints is the best intensive land use pattern for Dianchi Lake basin.
Fourthly, the built-up area in scenario 3 becomes larger than that in scenario 1 as the cumulative percentage declines. This indicates that the land use optimization and adjustment policy (e.g., village relocation and consolidation, and increasing urban land and decreasing rural land) results in more intensive land use. However, as the growth rate increases, especially in large cities, the CTV development (without ecological constraints) has a probability of $70 \%$ to lose control because of the encroaching on ecological land, i.e., the CTV development exceeds the ecosystem carrying capacity in the study area.

Fively, the existing CTV development (i.e., scenario 1) in Dianchi Lake basin is unsustainable. According to the results from scenario 4, the internal structure and the external morphology of CTV would be more compact under the promise of maintaining most of the ecological land, especially the wetland and lake protection barrier. Moreover, increasing the ratio of CTV and improving the land utilization rate may help protect the ecological environment, maintain CTV development, and achieve the intensive land use to the highest degree in the study area.

Finally, we need to properly control the population growth and expansion of development area to make development of the Dianchi Lake basin sustainable. Population and construction area can be regarded as two indicators of CTV development. The simulation results show that by 2020, there would be a healthy cycle of CTV development and ecosystem in Dianchi Lake basin if the population is capped to 5 million (vs. 6.2 million under the current plan by the Kunming Municipality Government), and the built-up area under 608 $\mathrm{km}^{2}$. As for the central area of Kunming, which already has high population density and intensive land use, the population and built-up area should be controlled to 4 million and 380 $\mathrm{km}^{2}$, respectively (vs. 5 million and $430 \mathrm{~km}^{2}$ under the current plan) by 2020 .

\section{REFERENCES}

[1] B. Fu and L. Chen, "The effect of land use chang on the regional enviornment in the Yangjuangou catchmengt in the Loess plateau of China,” Actc Ecologica Sinica, vol. 54(3), 1999, pp. 241-246.

[2] Y. Liu, G.Wu, and ZH.Gao, "Impact of land use chang in Fuxian and Qilu basins of Yunnan on lake water quality,” Chinese Journal of Ecolongy, vol. 27(3), 2008, pp. 447-453.

[3] H. Zhang, H. Li, and Z. Chen, "Analysis on land use dynamic change and its impact on the water environment in Dianchi lake drainage area," Research of Soil and Water Conservation, vol. 19(1), 2012, pp. 92-96.

[4] H. Zhang, Z. Chen, S. Zhang, and H. Li, "Heterogeneity of land use and water enviornment in plateau lake basin of Yunnan province," Bulletin of Soil and Water Conservation , vol. 32(2), 2012, pp. 255-266.

[5] Q. Guo, K. Ma, and Y. Zhang, "Impact of land use pattern on lake water quality in urban region,” Actc Ecologica Sinica, vol. 29(2), 2009, pp. 776-787.

[6] D. Liu, "Research on the Coordination of Ecological Environment and Land use in Langfang City,” Journal of the Environmental Management College of China-EMCC, vol. 2(13), 2011, pp. 26-29.

[7] Y. Zong, and B. Wang, "The innovative research of the 'harmoniousintensive' extent for urban ecoland," Scientific Management Research, vol. 26(6), 2005, pp. 32-35.

[8] X. Dong, S. Shi, and Q. Wang, "The critical analysis of intensive land use and ecology environment," Technology of Water and Soil Conservation, vol. 6(6),2006, pp. 33-34. 
[9] Q. Zhang, D. Li, and Y. Shao, "Study on the Coordinated Development between Land Use and Ecological Environment Based on Environmental Friendly Pattern,” Journal of Anhui Agriculture Science, vol. 37(23), 2009, pp. 11130-11132.

[10] W. Sun, W. Chen, and X. Duan, "The feasible development regionalization of land use based on the ecological-economic analysis approach in lakeshore city area-taking Wuxi as a case,” Journal of lake science, vol. 19(2), 2007, pp. 190-196.

[11] X. Liu, "Rural residential spot Spacial layout optimization and intensive land use research-take Beijing Changping as example," Master Dissertation 3. Master DissertationM.S. thesis, China University of Geosciences (Beijing), 2009.

[12] Q. Tang and L. Yu, "Study on village renovation pattern of land in Wugang City,” Economic Research Guide, vol. 27(101), 2010, pp. 51-53.

[13] S. Zhao, "Rethink about the intensive land use-based on Hongkong city intensive land use model research," China Land Science, vol. 23(8), 2009, pp. 73-77.

[14] X. Wu and J. Peng, "The 'San-jiu' Transformation Study Based on the Eco-city Concept: A Case of the 'San-jiu' Transformation of Dongguan City,” Urban Development Research, vol. 19(2), 2012, pp. 190-196.

[15] X. Yang, Y. Liu, and H. Wang, "Land utility planning layout model based on constrained conditions cellular automata,” Journal of Wuhan university, vol. 32(12), 2007, pp. 1164-1167.

[16] Q. Yang and X. Li, "dynamic constrained CA model for simulating complex urban systems," Geography and GEO-information Science, vol. 22(5), 2006, pp. 10-15.

[17] C. A. Jantz, S. J. Goetz, and M. K. Shelley, "Using the SLEUTH urban growth model to simulate the impacts of future policy scenarios on urban land use in the Baltimore-Washington metropolitan area,” Environment and Planning B:Planning and Design, vol. 31(9), 2003, pp. 251-271.

[18] X. Wu and Y. Hu, "Research for scenarios simulation of future urban growth and land use change in Shenyang City," Geographical research, vol. 28(5), 2009, pp.1265-1275.

[19] L. Tan, M. Li, Y. Liu, and W. Cai, "Study of land use simulation on the condition of ecological environment protection-A case research in Dianchi Basin in Kunming,” Journal of Nanjing forest university, vol. 33(5), 2009, pp. 60-64.

[20] Y. Liu, C. Wu, and W. Yue, "Applying SLEUTH for simulating urban expansion of Hangzhou,” Journal of Natural Resources , vol. 23(5), 2008, pp. 797-807.

[21] Y. Zhang, J. Li, and Y. Chen, "Simulation of Beijing Urbanization Using SLEUTH, remote sensing information," Remote sensing information, vol. 2(2), 2007, pp. 50-54.

[22] E. A. Silva and K. C. Clarke, "Calibration of the SLEUTH urban growth model for Lisbon and Porto, Portugal-Computers," Environment and Urban Systems, vol. 26 (6), 2002, pp. 525-552 